\title{
OPEN Identification and characteristics of combined agrometeorological disasters caused by low temperature in a rice growing region in Liaoning Province, China
}

\author{
Ruipeng $\mathrm{Ji}^{1,2 \bowtie}$, Wenying $\mathrm{Yu}^{1,2}$, Rui Feng ${ }^{1,2}$, Jinwen $\mathrm{Wu}^{1,2}$ \& Yushu Zhang ${ }^{1,2}$
}

Owing to climate change, agrometeorological disasters are becoming increasingly complex. Here, we analysed the characteristics of combined agrometeorological disaster (CAD) caused by low temperature in annual rice crops in Liaoning Province, China, from 1961 to 2017. We assessed the repeat occurrence of natural disasters on rice production. The results showed that (1) there were six possible CAD scenarios in a rice growing season. These included two scenarios with one disaster in two periods (OD-1, OD-2), three scenarios with two different disasters (TD-1, TD-2, TD-3) and one with multiple disasters (MD-1). Since 1961, the overall occurrence of the six CAD scenarios showed a downward trend. Among the six scenarios, TD-1 had the greatest distribution and occurred most frequently; (2) three possible single agrometeorological disaster (SAD) scenarios may occur during a rice growing season, delayed cold damage (SAD-d), frost damage at only one stage (SAD-f), steriletype cold damage at one stage (SAD-s). Since 1961, the SAD-d frequency decreased, whereas, since the mid-1980s, the SAD-f frequency increased; (3) SAD and CAD frequencies showed downward trends, with CAD declining more than SAD. The CAD geographical range and frequency were smaller than those of SAD. Rice damage in SAD-f and OD-1 scenarios showed no significant trend, but appeared to have slightly increased. The main agrometeorological disasters affecting rice production in Liaoning Province were delayed cold damage, frost damage or both; (4) a comparison of the rice yield reduction rates of years in which CAD or SAD occurred in more than $50 \%$ of stations in Liaoning Province revealed that the yield reduction rates associated with the former were greater than those associated with the latter. CAD had more types, and the occurrences and impacts were more complicated, than for SAD. Compared with SAD, the effects of CAD may be magnified in rice crops, leading to reduced yields.

Rice (Oryza sativa L.) is an important crop worldwide and is planted in a variety of environments from $35^{\circ} \mathrm{S}$ to $53^{\circ} \mathrm{N}$ and at altitudes of 0 to greater than $2000 \mathrm{~m}^{1}$. The Food and Agriculture Organization predicts that the world's population will grow by $34 \%$, resulting in another 2.3 billion people needing to be fed, by $2050^{2}$. Rice has become a main food crop in response to population growth ${ }^{3}$, and global rice production must increase by $0.6 \%-0.9 \%$ per year by 2050 to feed approximately half of the world's population ${ }^{4}$. Potential reductions in rice yields may result from meteorological, disease- and pest- related disasters ${ }^{5}$. Therefore, any fluctuations in rice yield owing to agrometeorological disasters will have a direct effect on world food security. To date, most studies have focused on a single rice-related agrometeorological disaster. For example, Shimono et al ${ }^{6,7}$ simulated a low temperature environment (water, air and estimated panicle temperatures) in a 4-year field experiment and found that low temperatures significantly increased rice sterility during the vegetative growth stage. Storms are also a major factor resulting in rice production losses in southwest Japan ${ }^{5}$. Tani ${ }^{8}$ indicated that the yield losses caused by storms were mainly the results of interactions between high wind speeds and heavy rainfalls. In the Yangtze River Basin and Southern China, Xiong et al..$^{9}$ studied the effects of droughts and floods, as well as their

\footnotetext{
${ }^{1}$ Institute of Atmospheric Environment, China Meteorological Administration, Shenyang 110166, China. ${ }^{2}$ Key Laboratory of Agrometeorological Disasters, Liaoning Province, Shenyang 110166, China. 花mail: jiruipeng@163.com
} 
reversal, on the physiological characteristics and yield composition of rice at the tillering stage; and found that the yields per plant in 2014 decreased by $29.5 \%, 11.4 \%$, and $37.7 \%$, respectively, indicating that drought has a greater effect than flooding. Using the A1B emission scenario of the Intergovernmental Panel on Climate Change and the normalized production damage index, Teixeira et al. ${ }^{10}$ simulated the global risk of heat stress and found that rice showed a high level of heat-stress-related damage under basic climatic conditions (1971-2000), especially in South Asia. Mamun et al. ${ }^{11}$ reported that low temperatures inhibit the development of rice microspores, leading to male sterility. Matsui et al. ${ }^{12}$ studied the differences in sterility in nine varieties of rice caused by high temperatures at the flowering stage and concluded that the most sensitive and the most tolerant varieties had their fertility levels reduced to $50 \%$ at approximately $37^{\circ} \mathrm{C}$ and $40^{\circ} \mathrm{C}$, respectively. For rice grown in China, cold and heat damage caused by low and high temperatures, respectively, are the main meteorological risks ${ }^{13}$. Crops are often affected by a variety of abiotic stresses at the same time, and their responses are unique. They cannot be directly inferred from exposure to a single abiotic stress ${ }^{14}$. Suzuki et al. ${ }^{15}$ found that the root temperature of rice at the seedling stage was an important factor in leaf responses and sensitivity of levels to low-temperature stress. They found that at the seedling stage an air temperature of $10^{\circ} \mathrm{C}$ and a root temperature of $25^{\circ} \mathrm{C}$ resulted in leaves having significant damage, which would also occur, or even be intensified, in a sunlit environment. Perdomo et al. ${ }^{16}$ assessed the single or combined effects of high-temperature and water-deficit stresses on plant growth, leaf gas exchange and water-use efficiency in the three most important crops in the world-rice, wheat and maize. They found that the accumulated total-crop growth decreased in all the treatments and that hightemperature and water-deficit stresses produce the most damage.

There have been some initial experimental studies and risk assessments of crop agrometeorological disasters. Keles and Öncel ${ }^{17}$ analysed the response of wheat seedlings to the combined stresses of low and high temperatures, as well as the combined stresses of flood, drought and salinity. They found that root and stem elongation decreased significantly under drought and salt-stress conditions. Additionally, low and high temperatures inhibited seedling growth under salt-stress conditions. Rollins et al.$^{18}$ showed that the effects of drought stress on the morphology and growth characteristics of barley were greater than those of heat stress. The latter alone had little effect on barley, whereas the effects of combined drought and heat stress were more serious than the either individual stress. Crops exposed to combined stresses generally have stronger responses, and experience more severe damage, than crops exposed to a single stress. Crops are affected, to different degrees, when multiple disasters occur simultaneously or successively. For instance, when drought and cold disasters occur simultaneously, the effects on crops are greater than the overall effects of the two disasters individually ${ }^{19}$. Combined heat and drought, and combined cold and drought, inflict serious damage to crops ${ }^{20}$. Liu et al. ${ }^{21}$ simulated the effects of low temperatures and drought on the growth and development of maize and found that the combination had a greater effect on yield than either single stress. Wu et al. ${ }^{22}$ indicated that the effects of the combined stress of an enhanced ozone content and ultraviolet B band radiation on soybean biomass and yield were greater than the simple additive effects of the two separate stresses. Wang et al. ${ }^{23}$ reported that the combined stress of soil waterlogging and high temperature significantly decreased wheat quality. Additionally, Wang et al. ${ }^{24}$ found that the effects of a combined high-temperature and drought stress on the physiological parameters of Bletillastriata were greater than those of each stress.

In response to global climate change, crop growth and development will be subjected to a greater range and quantity of environmental stresses, which may occur simultaneously and have serious consequences ${ }^{25}$. Previous studies of combined agrometeorological disaster (CAD) have mostly analysed plant stress experimentally, but few studies have been conducted under natural field conditions, especially for rice. Because the CAD occurrence characteristics under natural field conditions are still unclear, conclusions based on the effects of CAD obtained under experimental conditions on plant morphology, physiological traits, and yield may not be applicable for guiding practical agricultural production.

North-east China is an important rice production base. The main agrometeorological disasters that affect rice production are delayed cold damage (DCD), sterile-type cold damage (SCD) and frost damage (FD). There are many methods to identify single agrometeorological disasters, and several indices have been verified by measuring reductions in rice yields. Using the indices developed in previous studies, we identified the occurrences of single agrometeorological disaster (SAD) during rice production in Liaoning Province since 1961. The occurrences of CAD during rice production were then selected, and six scenarios were constructed. The temporal and spatial distributions of the six scenarios were analysed to provide a reference for further research into CAD.

\section{Materials and methods}

Area. The study site $\left(118^{\circ} 53^{\prime} \mathrm{E}-125^{\circ} 46^{\prime} \mathrm{E}\right.$ and $\left.38^{\circ} 43^{\prime} \mathrm{N}-43^{\circ} 26^{\prime} \mathrm{N}\right)$ is in Liaoning Province, in the south of northeast China, with an area $148,000 \mathrm{~km}^{2}$. It belongs to a temperate continental monsoon climate, with four distinct seasons. The annual mean temperature is $8.5^{\circ} \mathrm{C}$, the mean annual precipitation is $656 \mathrm{~mm}$ and there are $2520 \mathrm{~h}$ of sunshine annually. Liaoning Province, a semi-humid region, grows early-maturing rice in a single season, covering an area of 489,120 ha in 2019. The planted varieties are the japonica subspecies of cultivated rice in Asia, with 15-17 leaves. The growing season begins with seeding in April and ends with harvesting in September (Table 1). The main agrometeorological disasters are chilling and frost damage caused by abnormally low temperature.

Data. The meteorological and agricultural data, which were from the Liaoning Meteorological Bureau, included diurnal mean temperature, diurnal minimum temperature, and rice development stages from 52 stations in Liaoning Province (Fig. 1) from 1961 to 2017. The rice yield data were obtained from the Liaoning Provincial Bureau of Statistics or the Liaoning Provincial Statistical Yearbook (http://tjj.ln.gov.cn/tjsj/sjcx/ndsj/). The data were used to calculate the agrometeorological disasters affecting rice in Liaoning Province using the 


\begin{tabular}{|l|c|}
\hline Growing stage & Date range \\
\hline Seedling stage & 21, April-31, May \\
\hline Booting stage & 11, July-31, July \\
\hline Flowering stage & 1, August-31, August \\
\hline Milk stage & 1, September-31, September \\
\hline
\end{tabular}

Table 1. Main growth stages of rice.

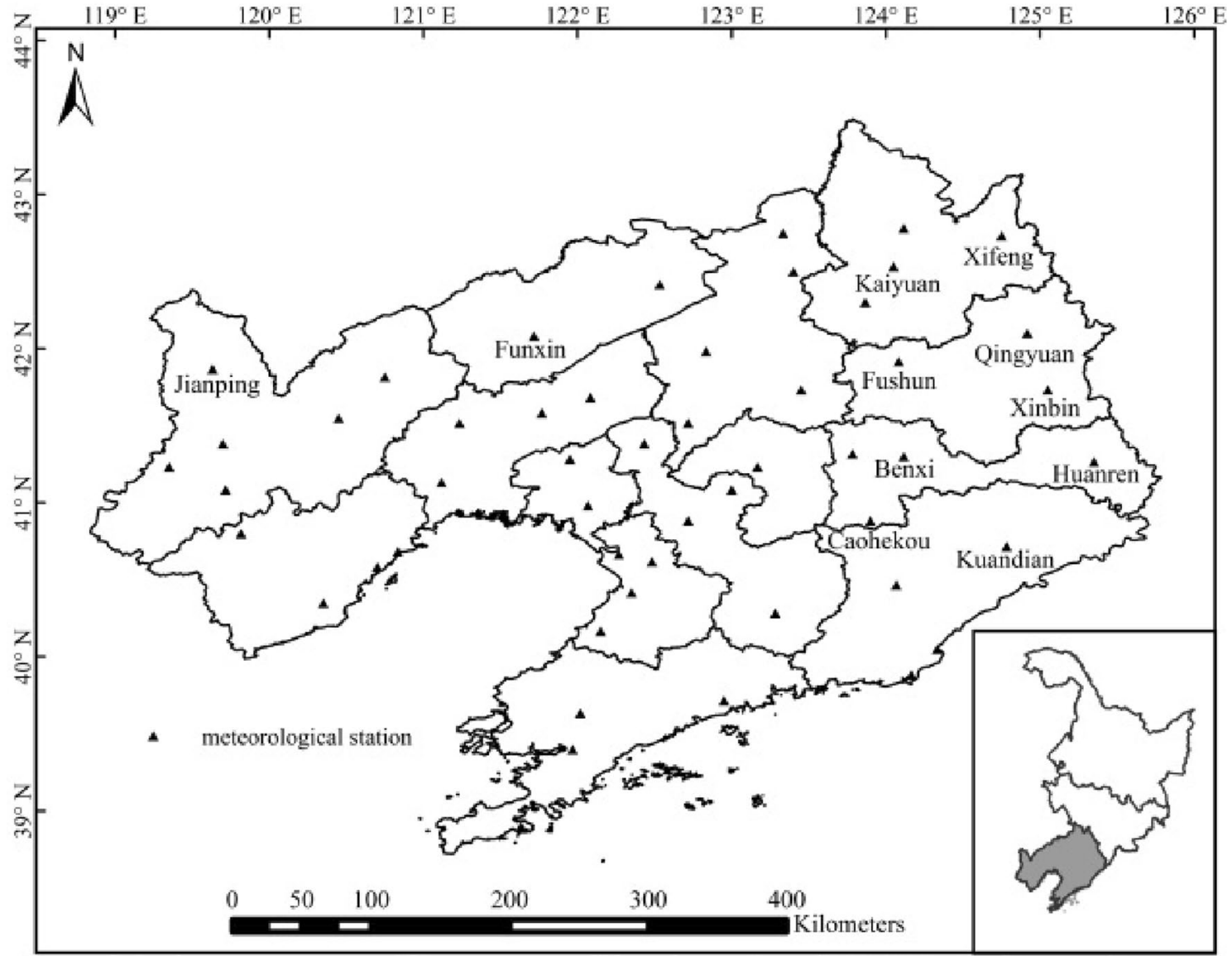

Figure 1. Location of 52 meteorological stations in Liaoning Province. Maps generated in ArcGIS 9.3.

methods provided in the next Section. The data were processed and charted in using Excel 2010 (Microsoft Corporation, Redmondm, WA, USA).

Methods. The following sections show the methods for calculating the indices for DCD, SCD and FD.

Delayed cold damage index of rice. The anomaly of the summed mean temperature from May to September $\left(\Delta T_{5-9}\right)$ is commonly used to calculate the DCD of rice in Northeast China ${ }^{26}$, and the calculation formula (Eq. 1) is:

$$
\Delta \mathrm{T}_{5-9}=\frac{\mathrm{T}_{5-9}}{\bar{\sum} T_{5-9}}
$$

where $\Delta T_{5-9}$ is the anomaly of the summed mean temperature from May to September (Table 2); $T_{5-9}$ is the

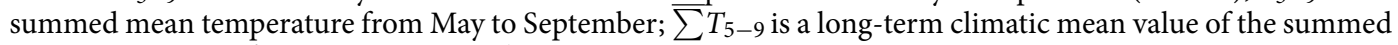
mean temperature from May to September.

Sterile-type cold damage index of rice. The rice sterile-type cold damage index (RSCDI) was used to calculate SCD in northeast $\mathrm{China}^{27}$, and the calculation formula (Eqs. 3, 4, 5) is: 


\begin{tabular}{|l|l|l|l|}
\hline Regional $\bar{\sum} \boldsymbol{T}_{5-9}\left[{ }^{\circ} \mathbf{C}\right]$ & Light cold damage $\Delta \boldsymbol{T}_{5-9}\left[{ }^{\circ} \mathbf{C}\right]$ & Moderate cold damage $\Delta \boldsymbol{T}_{5-9}\left[{ }^{\circ} \mathbf{C}\right]$ & Severe cold damage $\Delta \boldsymbol{T}_{5-9}\left[{ }^{\circ} \mathbf{C}\right]$ \\
\hline$\leq 83$ & -1.0 to -1.5 & -1.5 to -2.0 & $<-2.0$ \\
\hline $83.1-88$ & -1.1 to -1.8 & -1.8 to -2.2 & $<-2.2$ \\
\hline $88.1-93$ & -1.3 to -2.0 & -2.0 to -2.6 & $<-2.6$ \\
\hline $93.1-98$ & -1.7 to -2.5 & -2.5 to -3.2 & $<-3.2$ \\
\hline $98.1-103$ & -2.4 to -3.0 & -3.0 to -3.8 & $<-3.8$ \\
\hline $103.1-108$ & -2.8 to -3.5 & -3.5 to -4.2 & $<-4.2$ \\
\hline $108.1-115$ & -3.6 to -4.5 & -4.5 to -5.1 & $<-5.1$ \\
\hline$>115$ & -4.5 to -5.3 & -5.3 to -5.9 & $<-5.9$ \\
\hline
\end{tabular}

Table 2. Delayed cold damage (DCD) index of rice in different heat conditions.

\begin{tabular}{|c|c|c|c|}
\hline Types & Scenario & Disasters & Occurrence description \\
\hline \multirow{2}{*}{ One disaster in two periods (OD) } & One Disaster in two periods -1 (OD-1) & Frost damage (FD) & $\begin{array}{l}\text { Disasters occur simultaneously at seedling stage } \\
\text { and milk stage }\end{array}$ \\
\hline & One Disaster in two periods -2 (OD-2) & Sterile-type cold damage (SCD) & $\begin{array}{l}\text { Disasters occur simultaneously at booting stage } \\
\text { and flowering stage }\end{array}$ \\
\hline \multirow{3}{*}{ Two kinds of disasters (TD) } & Two kinds of Disasters-1 (TD-1) & Delayed cold damage (DCD) + Frost damage (FD) & $\begin{array}{l}\text { Disasters occur at seedling stage or milk stage, } \\
\text { and accumulated temperature is insufficient in the } \\
\text { growing season }\end{array}$ \\
\hline & Two kinds of Disasters -2 (TD-2) & $\begin{array}{l}\text { Delayed cold damage (DCD) + Sterile-type cold } \\
\text { damage (SCD) }\end{array}$ & $\begin{array}{l}\text { Disasters occur at booting stage or flowering } \\
\text { stage, and accumulated temperature is insufficient } \\
\text { in the growing season }\end{array}$ \\
\hline & Two kinds of Disasters - 3 (TD-3) & $\begin{array}{l}\text { Sterile-type cold damage (SCD) + Frost damage } \\
\text { (FD) }\end{array}$ & $\begin{array}{l}\text { Disasters occur at seedling stage or milk stage, } \\
\text { and occur at booting stage or flowering stage }\end{array}$ \\
\hline Multiple Disasters (MD) & Multiple Disasters -1 (MD-1) & $\begin{array}{l}\text { Delayed cold damage (DCD) + Sterile-type cold } \\
\text { damage (SCD + Frost damage (FD) }\end{array}$ & Three kinds of disasters occur simultaneously \\
\hline
\end{tabular}

Table 3. Occurrence scenarios for combined agrometeorological disaster (CAD) in the rice growing season in Liaoning Province.

$$
\begin{gathered}
\text { RSCDI }=\frac{\sum_{\mathrm{i}=1}^{\mathrm{n}} \mathrm{ST}}{\mathrm{SD}} \\
\mathrm{ST}=\frac{\mathrm{S}(\mathrm{t})}{0.54} \\
\mathrm{~S}(\mathrm{t})=\frac{\left(\mathrm{T}-\mathrm{T}_{1}\right)\left(\mathrm{T}_{2}-\mathrm{T}\right)^{\mathrm{B}}}{\left(\mathrm{T}_{0}-\mathrm{T}_{1}\right)\left(\mathrm{T}_{2}-\mathrm{T}_{0}\right)^{\mathrm{B}}} \\
\mathrm{B}=\frac{\mathrm{T}_{2}-\mathrm{T}_{0}}{\mathrm{~T}_{0}-\mathrm{T}_{1}}
\end{gathered}
$$

where RSCDI is rice sterile-type cold damage index, range [0,1); when RSCDI $<1$, cold damage may occur; ST is standardized temperature suitability calculated by formula (Eq. 3); $S(t)$ is the temperature suitability of day i calculated by formula (Eq. 4); SD is the duration days when $S(t)<0.54 ; n$ is the number of days; $T$ is actual mean temperature; $T_{2}, T_{1}, T_{0}$ represent diurnal maximum temperature, diurnal minimum temperature and the optimum temperature of rice at the booting stage or flowering stage, respectively; B is a coefficient calculated by formula (Eq. 5).

Frost damage index of rice. The FD is usually calculated by the diurnal minimum temperature. FD will occur when the diurnal minimum temperature of rice during the seedling stage or milk stage is lower than $0{ }^{\circ} \mathrm{C}$ in Liaoning Province.

Six scenarios of combined agrometeorological disaster for rice. A CAD is defined as follows: in the process of crop production, two or more types of meteorological disasters occur concurrently or alternately, or one type of meteorological disaster occurs in two or more different growth periods, resulting in crop losses ${ }^{28}$. The scenarios for CAD occurrence were based on three types: (1) one disaster in two periods (OD) scenario, where the same disaster occurred at different stages of rice production; (2) the two disasters (TD) scenario, where two kinds of disasters occurred in rice production; and (3) the multiple disasters (MD) scenario, where 
more than two kinds of disasters occurred during rice production. The scenarios for CAD in the rice growing season in Liaoning Province are shown in Table 3.

Three scenarios of single agrometeorological disaster for rice. The scenarios for SAD occurrence were as follows: (1) SAD-d, in which only DCD occurred during rice production; (2) SAD-s, in which SCD occurred at only one stage during rice production; and (3) SAD-f, in which FD occurred at only one stage during rice production.

Data processing. The DCD, SCD and FD were calculated in Liaoning Province between 1961 and 2017. The occurrence of CAD in the six scenarios and the occurrence of SAD in the three scenarios were identified from the data for DCD, SCD and FD. In calculating CAD statistics, when there was a MD in a certain station in one year, the TD was not counted; when there was a TD, then the OD was not counted.

This paper analysed the temporal and spatial distribution of CAD in Liaoning Province. The value of the ratio between the number of stations recording agrometeorological disasters and total stations (IOC) indicated the occurrence range of $\mathrm{CAD}$ in the region in regard to temporal variation. The frequency $(\mathrm{P}, \%)$, was the percentage of years with CAD out of the total years ${ }^{27}$. The occurrence range of CAD was divided into local, regional and large-scale categories; an IOC lower than 20\% was a local CAD; an IOC from 20\% to 50\% was a regional CAD; and an IOC greater than $50 \%$ was a large-scale CAD.

Annual reduction in agrometeorological yield of rice. On the basis of the per unit yield of rice from 1961 to 2017, the trend yield was fitted using a quadratic polynomial method ${ }^{26}$, and the rice yield was separated to calculate the yield reduction rate affected by agrometeorological disasters. The formulas $($ Eqs. $6,7,8)$ are:

$$
\begin{aligned}
& Y_{\mathrm{t}}=0.1247 x^{2}+13.803 x+150.7 \\
& Y_{\mathrm{w}}=Y_{\mathrm{a}}-Y_{\mathrm{t}} \\
& \Delta Y=Y_{\mathrm{w}} / Y_{\mathrm{t}}
\end{aligned}
$$

where $Y_{\mathrm{t}}$ is the trend yield, $x$ is the time series number $(1,2 \ldots \ldots), Y_{\mathrm{w}}$ is the agrometeorological yield, $Y_{\mathrm{a}}$ is the actual yield, $\Delta Y$ is the yield reduction rate.

\section{Results}

Temporal characteristics of combined agrometeorological disasters. The temporal variation of CAD was analysed in Liaoning Province from 1961 to 2017 using the IOC (Fig. 2). The maximum IOC for OD-1 was 0.231 occurring in 2017; there were 32 years with OD-1 at $1-12$ stations. FD occurred at the seedling stage and the milk stage. There was no OD-2 in the past years (Fig. 2a).

TD-1 happened in 35 out of the past 57 years, when DCD and FD both occurred in the same rice growing season. The maximum IOC of TD-1 was 0.635 and it occurred in 1987. TD-2 happened in 3 years, when SCD occurred at the booting or flowering stage and DCD occurred during rice production. The maximum IOC of TD-2, a value of 0.038 , occurred in 1977. A total of 20 years had TD-3 during rice production, with SCD in the booting or flowering stage, and FD in the seedling or milk stage. The maximum IOC of TD- 3 was 0.115 , in 1984 (Fig. 2b).

Between 1961 and 2017, the maximum IOC of MD-1 was 0.25, which happened in 1977. A total of 20 years showed evidence of the MD-1 scenario, when SCD, DCD and FD occurred simultaneously in the rice growing period (Fig. 2c).

From 1961 to 2017, TD-1 had the most years of occurrence among the six scenarios, followed by OD-1. TD-1 was the most widely distributed of the six scenarios, and TD-2 was the least frequent and least widespread. There was no occurrence of OD-2. In the past 57 years, the IOC values of the four scenarios have generally shown a downward trend, apart from the OD-1 scenario which showed an upward trend. From 1961 to 2000, TD-1 was the most widely distributed among the six scenarios; the distributions of most scenarios except OD-1 were smaller from 2001 to 2017.

Only TD-1 occurred over a large-scale grade in the six scenarios. There was one year at a regional level for OD-1 and 3 years for TD-1. Regionally, MD-1 occurred in 1972 and 1977 (Table 4). The scale of CAD was local in other years.

Spatial distribution of combined agrometeorological disasters. The six scenarios for rice CAD were mainly located in the northwest and northeast of Liaoning Province from 1961 to 2017 (Fig. 3). Three sites (Xifeng, Jianping, Xinbin) had an OD-1 frequency greater than $20 \%$ and three sites (Fushn, Huanren, Caohekou) had an OD-1 frequency ranging from $10 \%$ to $20 \%$; the frequency at the other 46 sites was low $(\mathrm{P} \leq 10 \%)$. The frequency of OD-2 was always less than $10 \%$. For TD-1, nine sites had a frequency higher than $20 \%$, and these were mainly distributed in northwest and east Liaoning Province. Eighteen sites had a frequency between $10 \%$ and $20 \%$ in northwest, central and east Liaoning; the frequency of the other 25 sites was low $(\mathrm{P} \leq 10 \%)$. For TD-2, no site had a frequency greater than $10 \%$. For TD-3, one site (Jianping) had a frequency greater than $20 \%$, two sites (Xifeng, Xinbin) had a frequency ranging from $10 \%$ to $20 \%$, and 49 sites had a frequency under $10 \%$. One site (Jianping) had and MD-1 frequency greater than $20 \%$ and one site (Xinbin) had an MD-1 frequency between $10 \%$ and $20 \%$. 

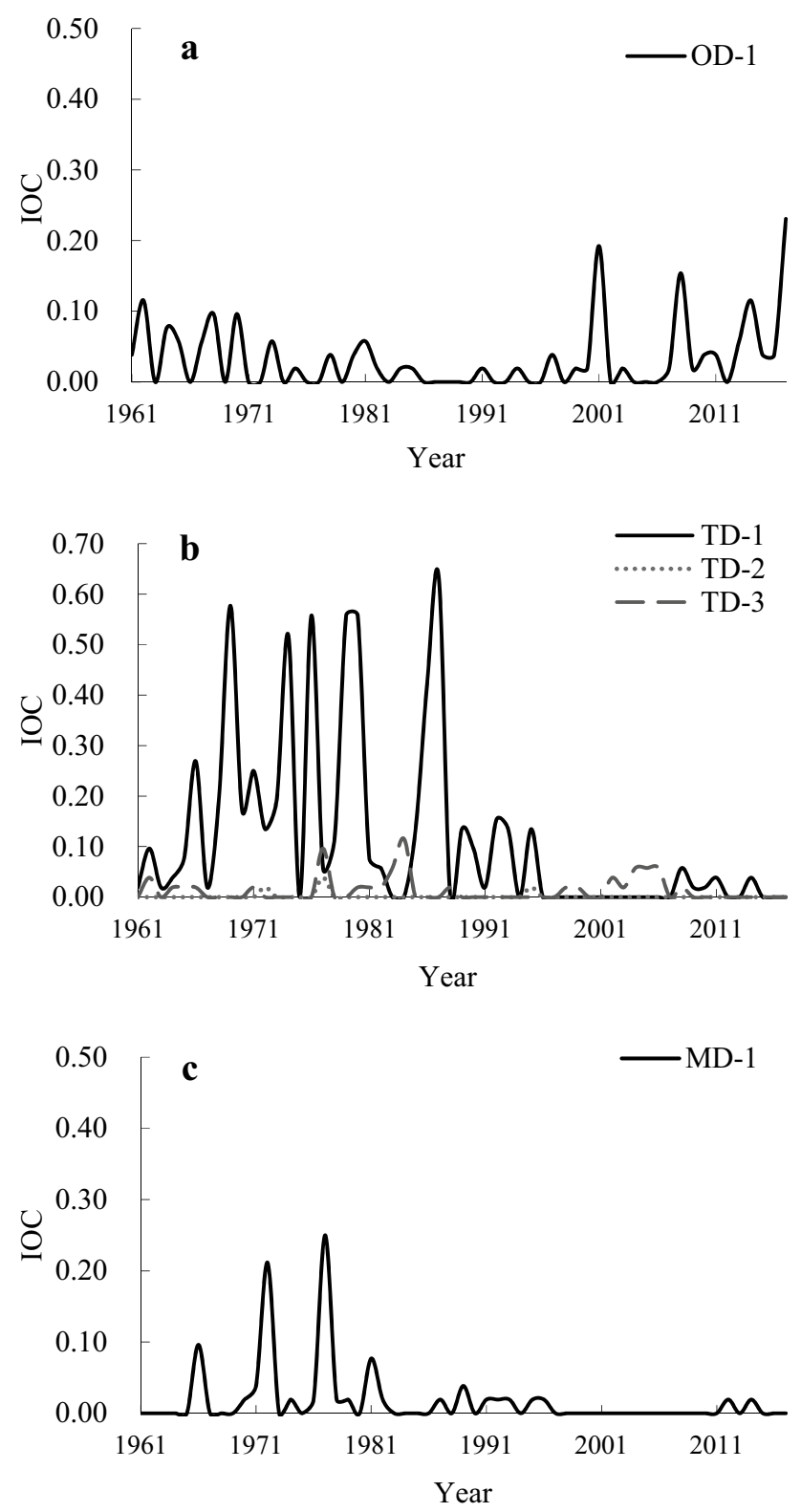

Figure 2. IOC (ratio between cold damage stations and total stations) for combined agrometeorological disasters (CAD) in different scenarios (a one disaster in two periods, OD; b two kinds of disasters, TD; c multiple disasters, MD).

\begin{tabular}{|l|l|l|}
\hline Scenario & Large-scale grade & Regional grade \\
\hline OD-1 & - & 2017 \\
\hline TD-1 & $1969,1974,1976,1979,1980,1987$ & $1966,1971,1986$ \\
\hline TD-2 & - & - \\
\hline TD-3 & - & - \\
\hline MD-1 & - & 1972,1977 \\
\hline
\end{tabular}

Table 4. Occurrence years of large-scale and regional combined agrometeorological disaster (CAD) in Liaoning Province. 

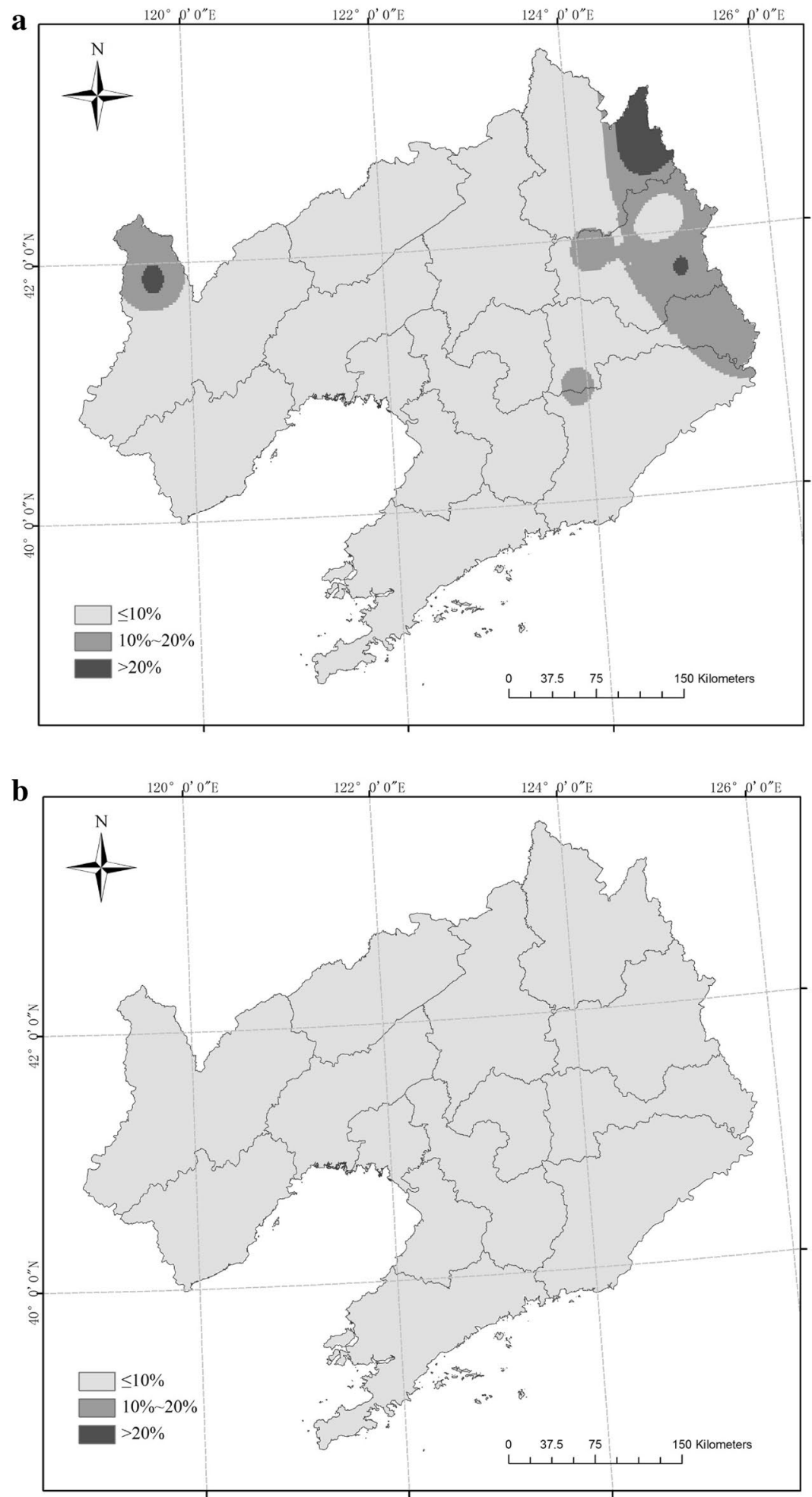

Figure 3. Frequency of combined agrometeorological disasters (CAD) in different scenarios (a OD-1, b OD-2, c TD-1, d TD-2, e TD-3, f MD-1). Maps generated in ArcGIS 9.3. 

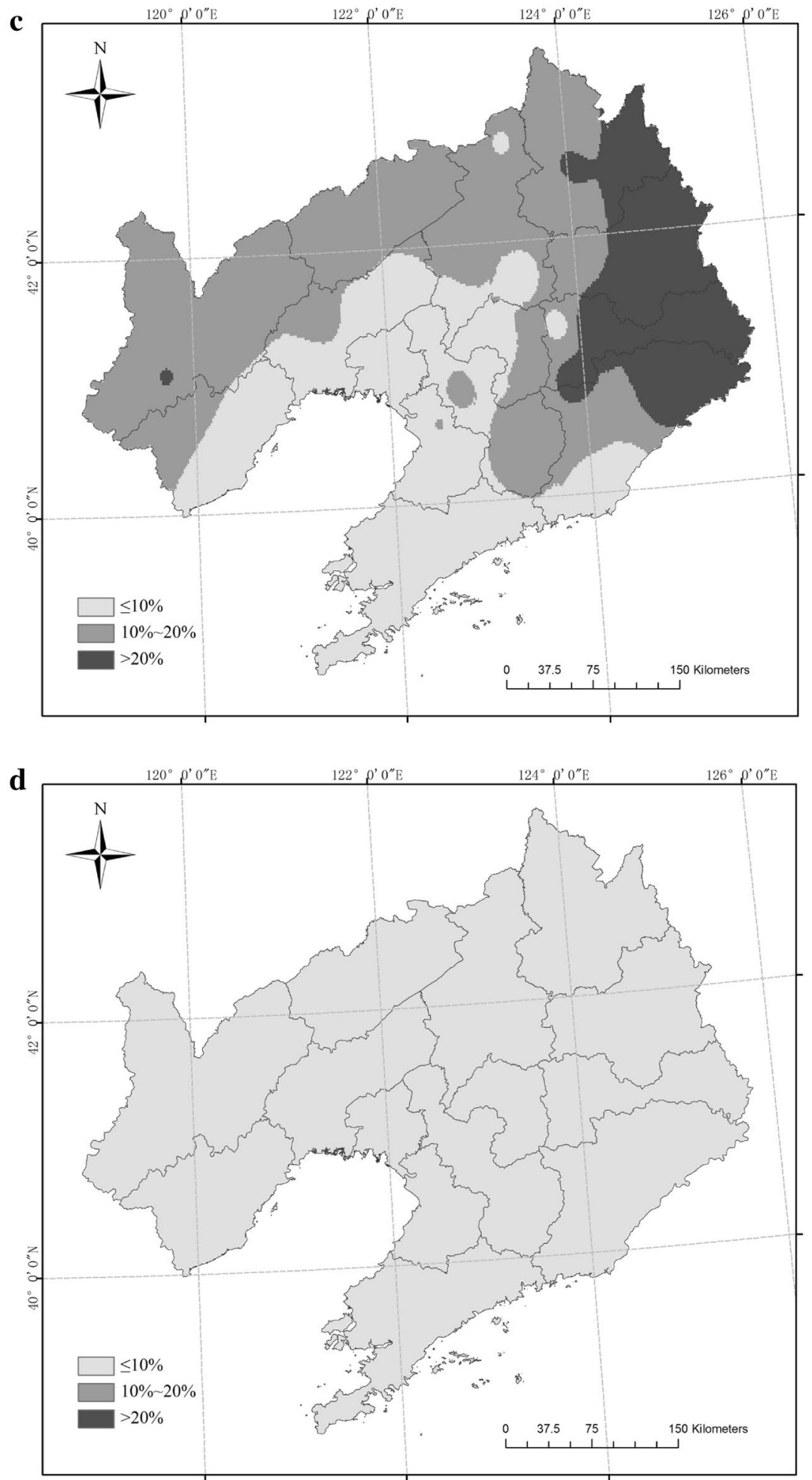

Figure 3. (continued) 

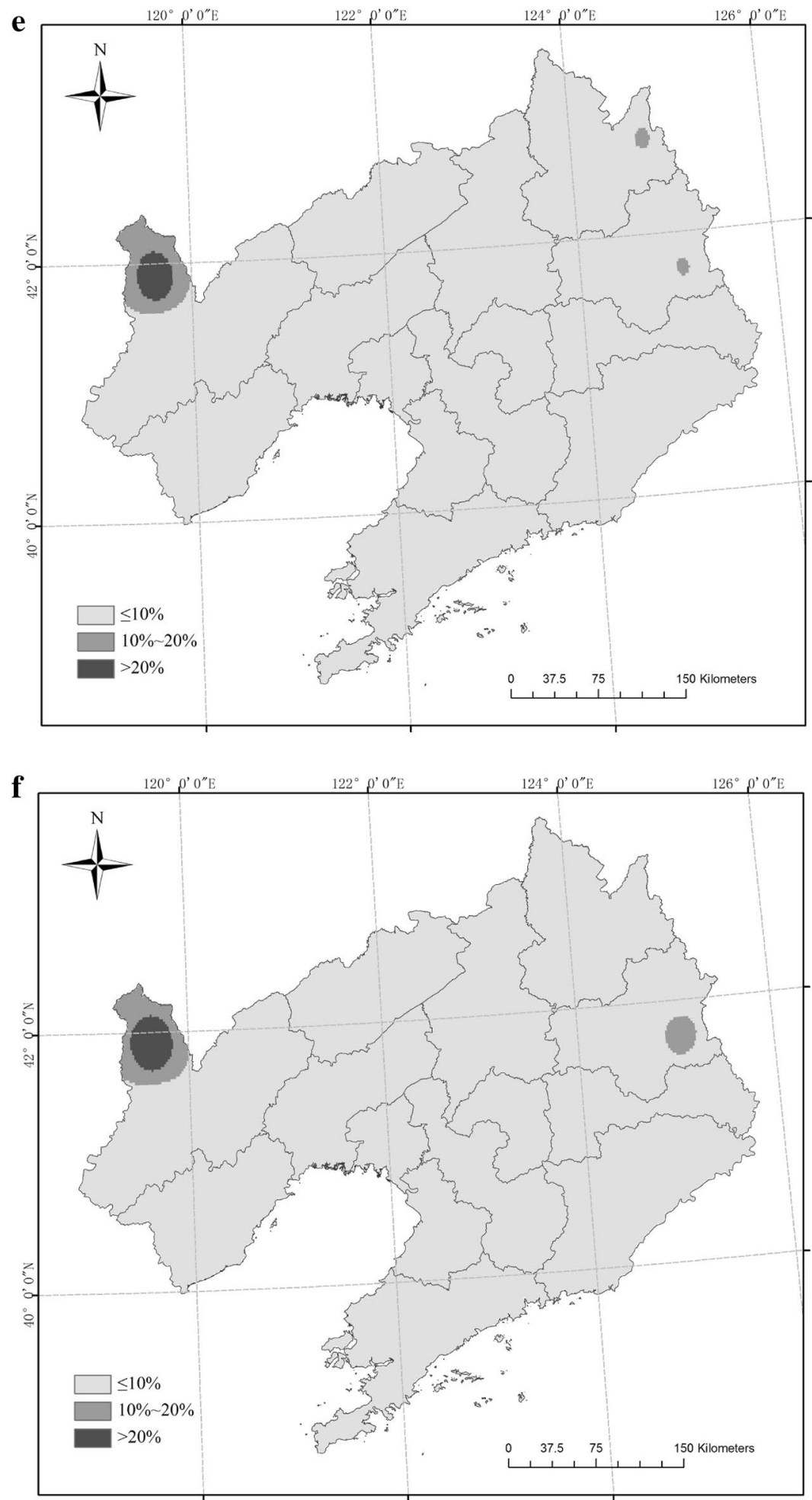

Figure 3. (continued)

\section{Discussion}

Characteristics of the single agrometeorological disaster scenarios. SAD-f occurred in 49 out of 57 years at different spatial scales, with a maximum IOC of 0.519 in 2013; SAD-d occurred in 33 years with a maximum IOC value of 0.808 in 1995; SAD-s occurred in 5 years, with a maximum IOC value of 0.115 in 1977 (Fig. 4). SAD-d showed a declining trend over the past 57 years, but the SAD-d frequency was higher than SAD-f and SAD-d. Since the mid-1980s, the frequency of SAD-f has increased, while the frequency and scale of SAD-s were relatively small. 


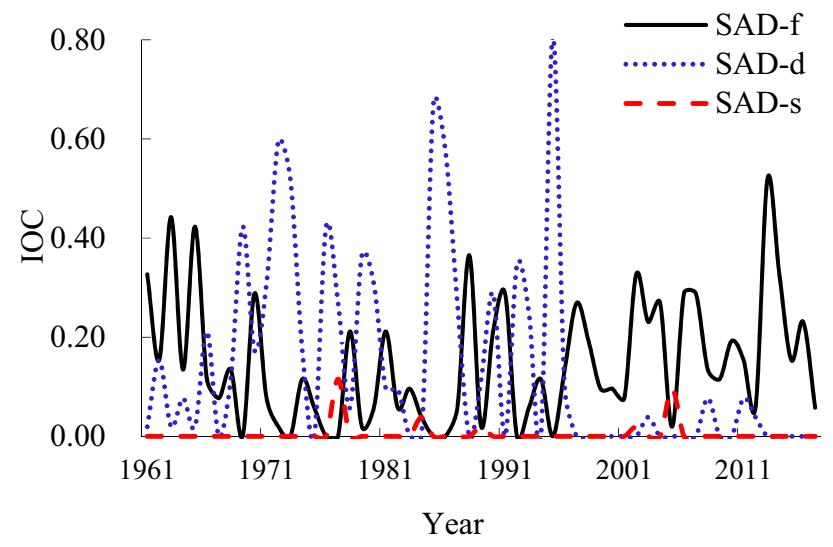

Figure 4. IOC change curve for single agrometeorological disasters (SAD) in different scenarios.

\begin{tabular}{|l|l|l|}
\hline Scenario & Large-scale grade & Regional grade \\
\hline SAD-f & 2013 & $\begin{array}{l}1961,1963,1965,1970,1978,1981,1988,1990,1991,1997,2002,2003,2004,2006,2007,2014, \\
2016\end{array}$ \\
\hline SAD-d & $1972,1973,1985,1986,1995$ & $1966,1969,1971,1976,1977,1979,1980,1987,1990,1992,1993$ \\
\hline SAD-s & - & - \\
\hline
\end{tabular}

Table 5. Occurrence years of large-scale and regional single agrometeorological disaster (SAD) in Liaoning Province.

A large-scale grade SAD-f event occurred in 2013 in Liaoning Province, and regional SAD-f occurred in 17 years. Five years showed a large-scale SAD-d and 11 years had regional SAD-d. There were no large-scale and regional years for SAD-s (Table 5).

The occurrence of SAD-f was recorded at 15 sites with a frequency greater than $20 \%, 13$ sites with frequency in the 10\%-20\% range, and 24 sites with a low frequency (P $\leq 10 \%)$ in Liaoning Province from 1961 to 2017 (Fig. 5). SAD-d occurred at 12 sites with a frequency higher than $20 \%, 22$ sites with frequency between $10 \%$ and $20 \%$, and 18 sites with a low frequency $(\mathrm{P} \leq 10 \%)$. In the three scenarios, the occurrence frequency and distribution of SAD-f was the highest and SAD-s was the lowest.

Comparison of the characteristics of single agrometeorological disasters and combined agrometeorological disasters. The maximum IOC of SAD was 0.808 in 1995 and the mean value was 0.294 for the 57 years of the study; the maximum IOC of CAD was 0.654 in 1987, and the mean value was 0.180 over the past 57 years; SAD and CAD occurred in all 57 years (Fig. 6). Both SAD and CAD showed declining trends from 1961 to 2017. The IOC was lower for CAD than for SAD for 42 years and higher than SAD for 14 years.

This paper analysed the mean IOC of SAD and CAD over six decades and found that the interdecadal mean value of the IOC in CAD was lower than that of SAD over five of the periods, but the IOC of SAD was lower than that of CAD in 1971-1980 (Fig. 7). The IOC of SAD showed a decreasing trend from the 1970s to the 2010s but showed an increasing trend after 2011. The IOC of CAD showed a decreasing trend from the 1970s to the 2000s, but showed an increasing trend after 2001 (Fig. 7).

There was one site (Fushun) with a SAD frequency of more than 50\% in Liaoning Province from 1961 to 2017, 42 sites with a frequency between $20 \%$ and $50 \%$, and nine sites with a frequency lower than $20 \%$. There were four sites (Xinfeng, Jianping, Xinbin and Caohekou) with a CAD frequency higher than 50\%, 13 sites with a frequency in the range $20 \%-50 \%$, and 35 sites with a frequency lower than $20 \%$ (Fig. 8). The frequency and range of $\mathrm{CAD}$ were less than those of $\mathrm{SAD}$.

There has been little research into the temporal or spatial distribution of CAD for rice and its occurrence characteristics: most research has been on SAD. For example, studies have examined the characteristics of SCD, DCD, FD for rice in northeast China ${ }^{26,27,29}$, and the risk of multiple disasters for rice in northeast China ${ }^{30,31}$. Han et al..$^{31}$ analysed the risk of disaster using the reduction rate of rice yield in Liaoning Province from 1980 to 2011, and found that the high-risk areas were distributed in the west and northeast of Liaoning Province; higher rates of yield reduction in lean years were mainly found in western Liaoning and its surrounding areas. In this study, a higher frequency of CAD was mainly distributed in the northwest of Liaoning Province, while that of SAD occurred in the northeast of Liaoning Province. The median frequency of CAD occurred in the northwest and northeast of Liaoning Province, while that of SAD covered most areas in Liaoning Province. The range of medium and higher frequency occurrence in CAD was consistent with the distribution of high-risk and high yield reduction areas in the study of Han et al. ${ }^{31}$. Therefore, it can be speculated that the CAD scenarios might magnify the effect of each single disaster, and, therefore, CAD would more easily lead to a higher reduction in the rice yield. 

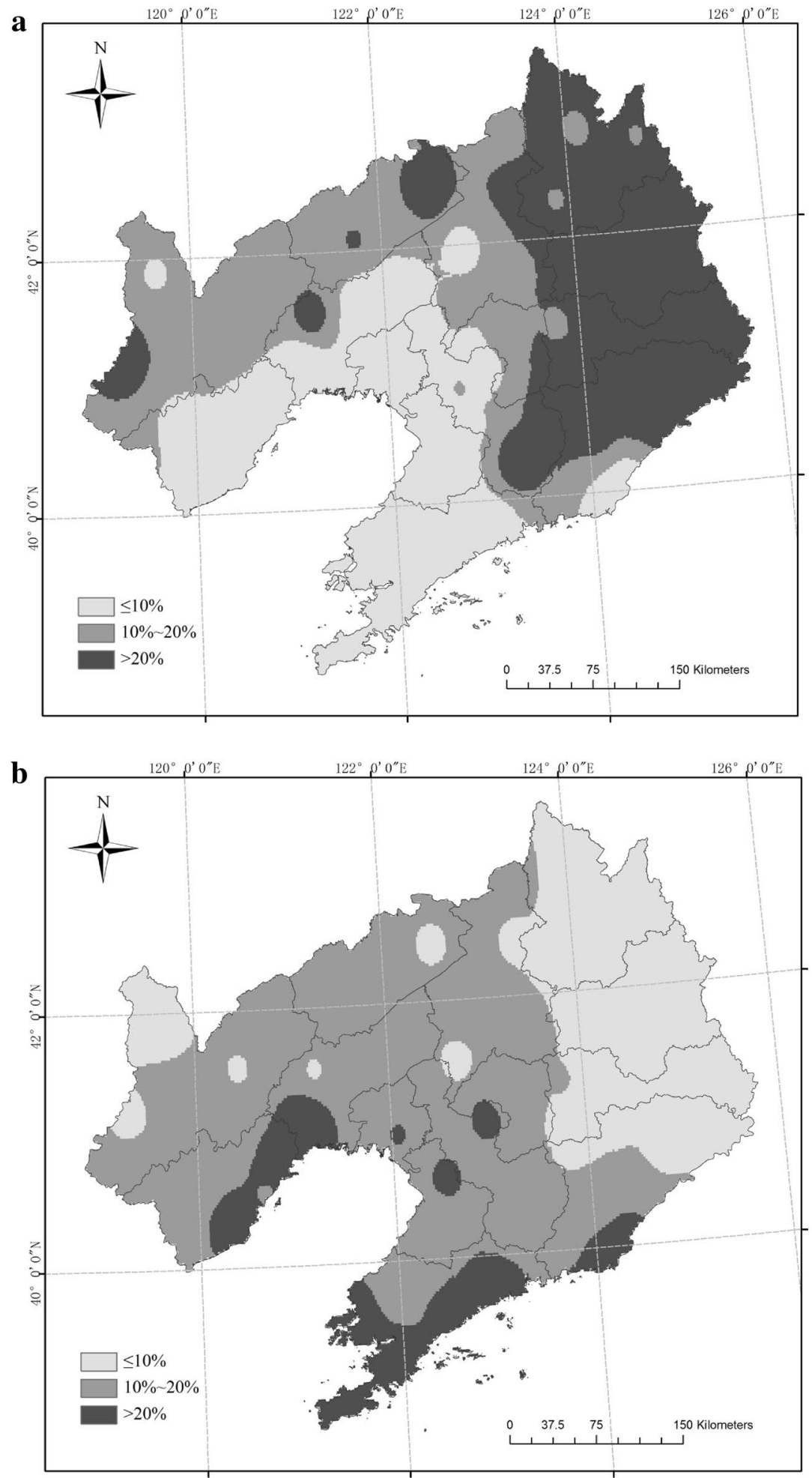

Figure 5. Frequency of single agrometeorological disasters (SAD) in different scenarios (a SAD-f, b SAD-d, c SAD-s). Maps generated in ArcGIS 9.3. 


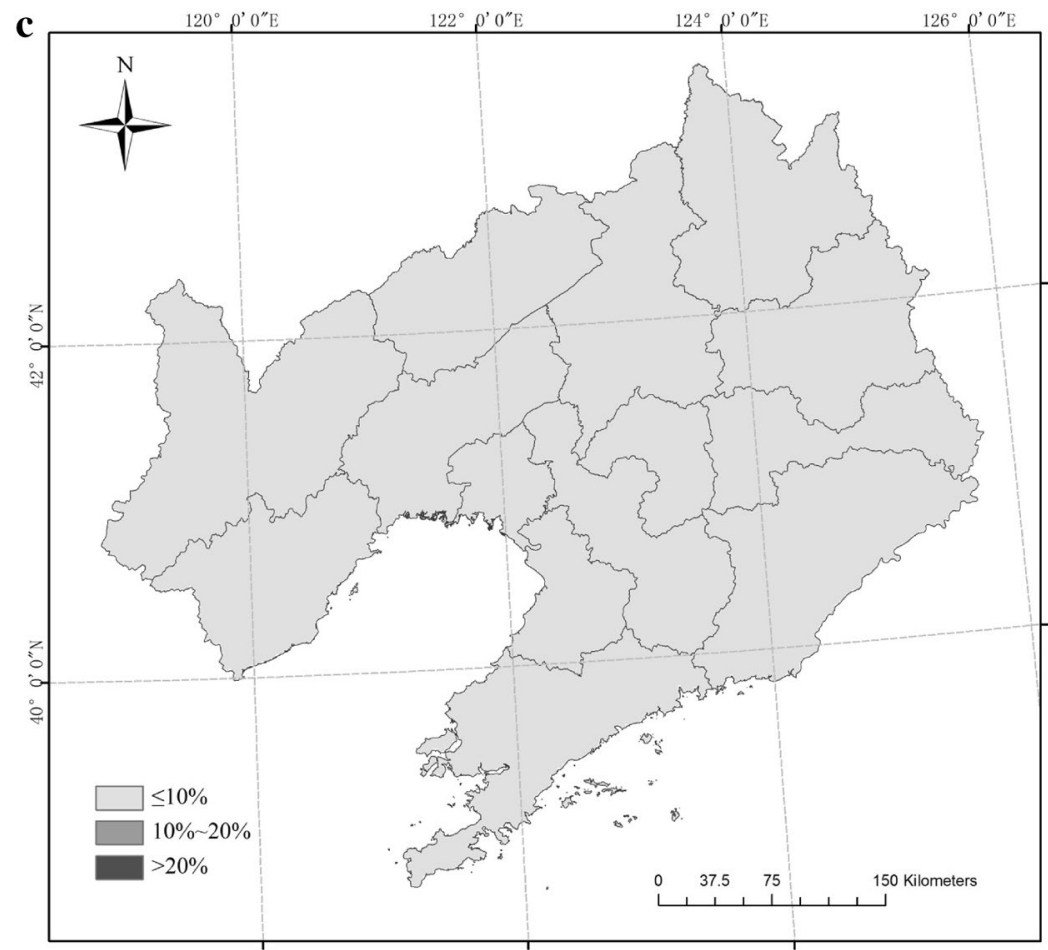

Figure 5. (continued)

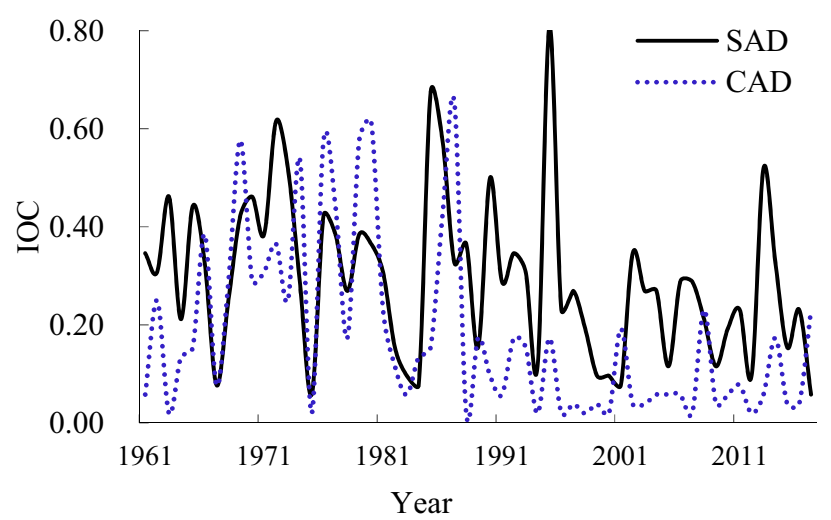

Figure 6. Change in the IOC for agrometeorological disasters in rice crops.

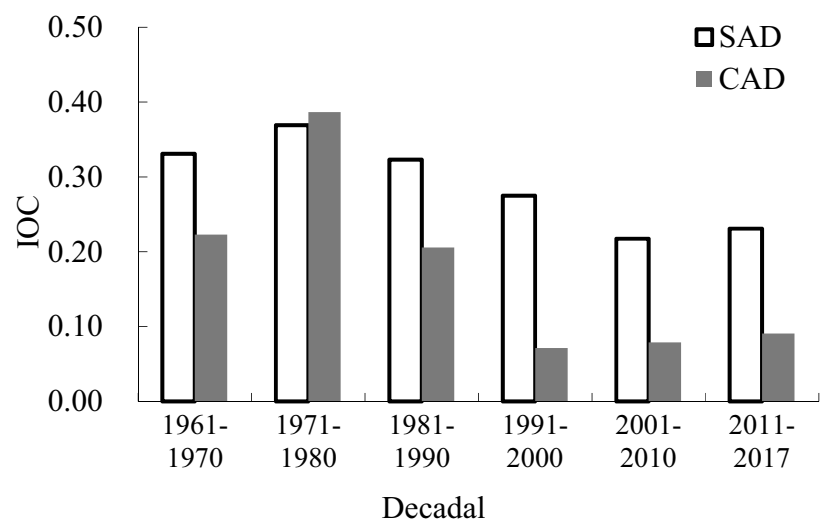

Figure 7. Interdecadal mean value of IOC for agrometeorological disasters in rice crops. 

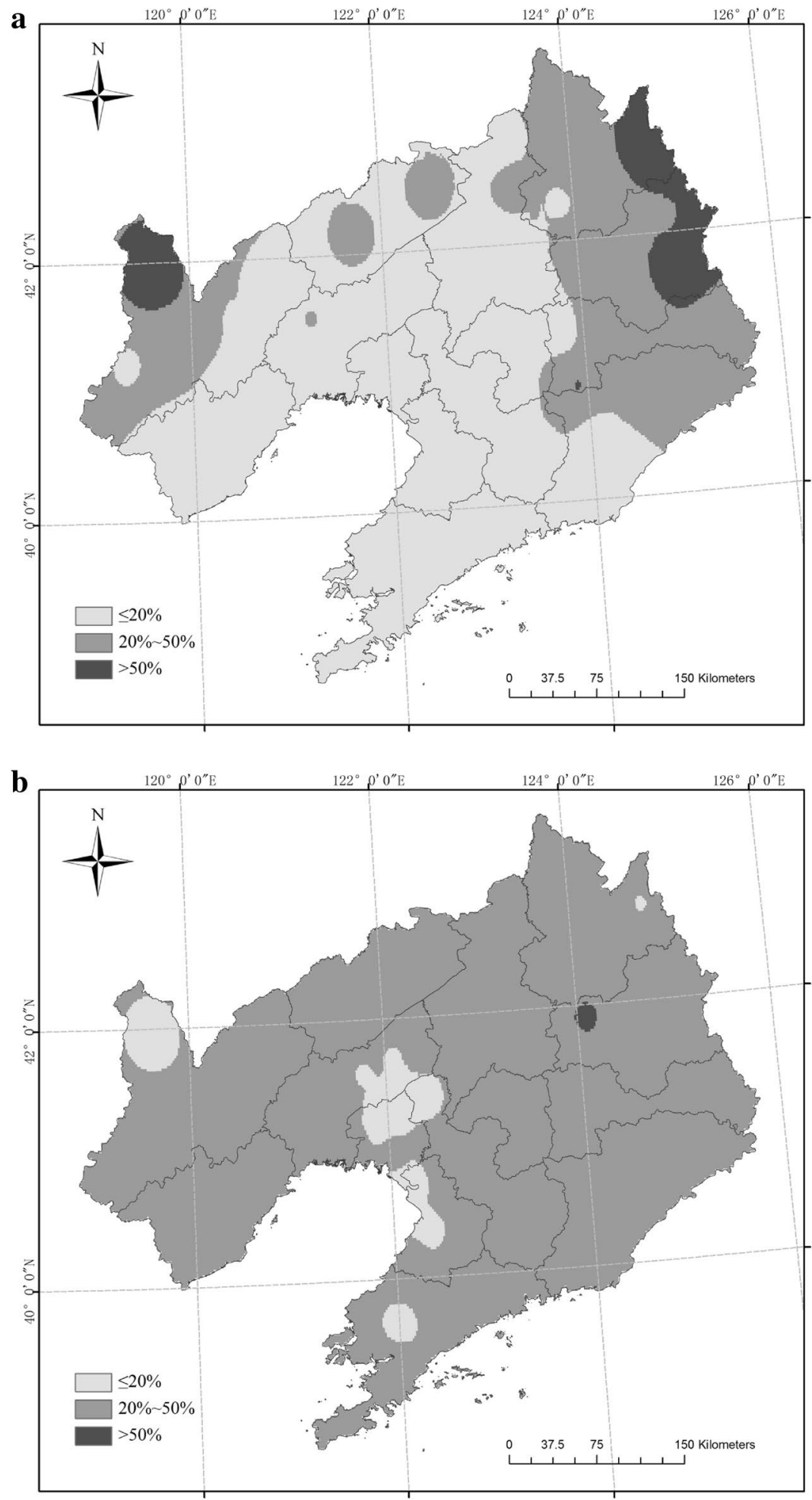

Figure 8. Frequency of agrometeorological disaster in rice crops (a combined agrometeorological disaster (CAD), b single agrometeorological disaster (SAD)). Maps generated in ArcGIS 9.3.

Comparison of the occurrence of single agrometeorological disasters and combined agrometeorological disasters. During the rice growing season in Liaoning Province, there were three scenarios of $\mathrm{SAD}$ and six scenarios of CAD. Compared with SAD, CAD had more scenarios and more complex processes, and its effect on rice was more difficult to evaluate. In SAD, the occurrence frequency and distribution of SAD-f and SAD-d were both high, when FD and DCD occurred alone in only one rice growth stage. In CAD, the occurrence frequency and distribution of TD-1, when FD and DCD occurred simultaneously, was the highest in the 


\begin{tabular}{|c|c|c|c|c|c|c|}
\hline Year & Yield reduction rate (\%) & IOC for all disasters & Station numbers in CAD & Station numbers in SAD & $\begin{array}{l}\text { CAD types (station } \\
\text { numbers) }\end{array}$ & $\begin{array}{l}\text { SAD types (station } \\
\text { numbers) }\end{array}$ \\
\hline 1961 & 23.5 & 0.40 & 3 & 18 & OD-1(2), TD-1(1) & SAD-f (17), SAD-d (1) \\
\hline 1962 & 21.8 & 0.56 & 13 & 16 & OD-1(6), TD-1(5), TD-3(2) & SAD-f (8), SAD-d (8) \\
\hline 1969 & 34.6 & 1 & 30 & 22 & TD-1(30) & SAD-d (22) \\
\hline 1972 & 29.1 & 0.98 & 19 & 32 & TD-1(7), TD-2(1), MD-1(11) & SAD-f (1), SAD-d (31) \\
\hline 1976 & 15.6 & 1 & 30 & 22 & TD-1(29), MD-1(1) & SAD-d (22) \\
\hline 1985 & 12.6 & 0.83 & 8 & 35 & OD-1(1), TD-1(7) & SAD-d (35) \\
\hline 1989 & 22.0 & 0.33 & 9 & 8 & TD-1(7), MD-1(2) & $\begin{array}{l}\text { SAD-f (1), SAD-d (6), SAD-s } \\
(1)\end{array}$ \\
\hline 1995 & 25.1 & 0.98 & 9 & 42 & TD-1(7), TD-2(1), MD-1(1) & SAD-d (42) \\
\hline 2006 & 12.7 & 0.35 & 3 & 15 & TD-3(3) & SAD-f (15) \\
\hline 2010 & 14.8 & 0.25 & 3 & 10 & OD-1(2), TD-1(1) & SAD-f (10) \\
\hline
\end{tabular}

Table 6. Comparison of agrometeorological disasters in years having greater than $10 \%$ rice yield reduction rates in Liaoning Province. IOC: ratio of the number of stations recording agrometeorological disasters to total stations, $C A D$ : combined agrometeorological disasters, $S A D$ : single agrometeorological disaster.

six scenarios. A single or combined occurrence of FD and DCD was most common disaster for rice in Liaoning Province. The occurrence frequency and distribution of OD-1 were both smaller than that of SAD-f, indicating that the occurrence was lower when FD happened at both the seedling and milk stages. SAD-s and OD-2 had the lowest frequency and range in all scenarios, indicating that DSD rarely appeared in SAD and CAD. The occurrence of SCD was not major disaster in the growth and development of rice in Liaoning Province, but the occurrence of DCD or FD, or both, was.

In this study, the occurrence frequency and range of SAD and CAD for rice showed declining trends in most sites over the past 57 years, which was consistent with the results of other studies. Studies on rice DCD and SCD concluded that cold damage events of rice in most areas of northeast China showed decreasing trends $\mathrm{s}^{26,27}$. Because of events such as climate warming, earlier warming in spring, delaying first frost dates and fewer low temperature days in summer, the trend of disasters was lower in rice planting areas ${ }^{30}$. However, although rice disasters showed a decreasing trend, local disasters may increase because of the frequent occurrence of climate anomalies. SAD-f and OD-1 scenarios in this study showed no significant decreasing trend, and even a partial increasing trend. Jiang et al. ${ }^{29}$ believed that the possibility of frequent SCD in north-east China was still high. According to $\mathrm{Xi}$ et al. ${ }^{32}$, cold periods would still occur in the growing season of rice in northeast China. Hu et al. ${ }^{33}$ concluded that the increase of SCD in northeast China was mainly because of the increase of climate variability, and most of the sites with increases were located in areas with decreasing temperature or no obvious trend of temperature increase.

Rice is a higher temperature-loving crop, which is mainly restricted by temperature conditions during its growing season. Liaoning Province is in the south of the rice planting area of the colder regions in China. Because of the relatively low latitude, heat conditions during the rice growing season were better than those in Jilin and Heilongjiang to the north of Liaoning Province. The climatic risk of cold damage in the rice growing season was lower than other regions in northeast China ${ }^{34}$. The occurrence of CAD was generally caused by low temperatures, which were the dominant factor. When two or more disasters occur together, there is a coupling or amplifying effect on rice growth compared with a single disaster.

A comparison of the rice yield reduction rates in the years when CAD or SAD occurred in more than $50 \%$ of stations in Liaoning Province revealed that the former happened in 5 years, 1969, 1974, 1976, 1980 and 1987, whereas the latter happened in 7 years, 1972, 1973, 1985, 1986, 1990, 1995 and 2013. When CAD was the major occurrence, the average yield reduction rate in the five years was $10.6 \%$. The yield reduction rate in 1969 was $34.6 \%$, which was the highest in the past 57 years. When SAD was the major occurrence, the average yield reduction rate in the seven years was $9.8 \%$. The average yield reduction rate in the years when CAD dominated was greater than in the years when SAD dominated. Therefore, it can be speculated that CAD has a greater effect on rice growing than any single disaster within CAD. However, it is difficult to quantify the effect on rice yield of $\mathrm{CAD}$, and further controlled field experiments should be conducted to verify these. It is difficult to control field experiments that are limited by conditions and facilities.

Comparison of the occurrence of agrometeorological disasters in years having rice yield reductions. On the basis of the rice yield reduction rate in calculations Liaoning Province from 1961 to 2017, a total of 10 years (Table 6) were screened. Six years had large-scale disasters (including SAD and CAD) and four years had regional disasters. In 1969, which showed the highest yield reduction rate (34.6\%), 30 sites had TD-1 disasters and the other 22 sites had SAD-f disasters. In 1972, the second highest reduction year (29.1\%), 11 sites had MD-1 disasters, i.e. three kinds of disasters occurred, seven sites had TD-1 disasters, one site had a TD-2 disaster, 31 sites had SAD-d disasters, one site had a SAD-f disaster, and only one station had no disaster. The TD-1 disaster, i.e. delayed cold damage and frost injury, was the most frequent CAD over the years, and SAD-d, i.e., delayed cold damage, was the most frequent SAD. The occurrence of single and combined agrometeorological disasters in different regions strongly affected the rice yield. Generally, the larger the disaster range, the 


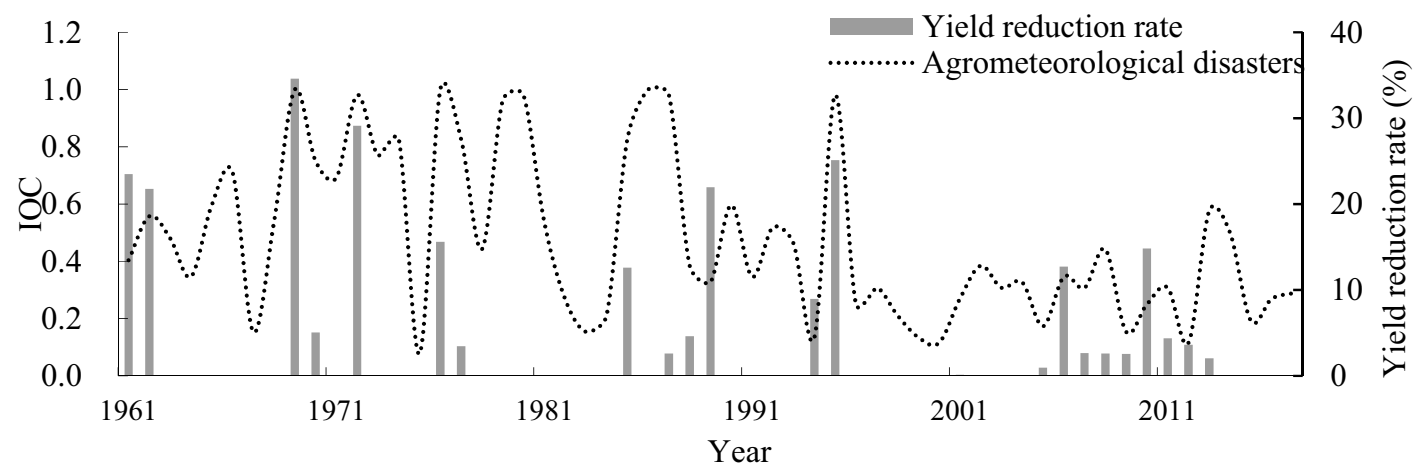

Figure 9. The IOC change curve of all agrometeorological disasters and the rice yield reduction rate from 1961 to 2017 .

higher the yield reduction. However, some years were not completely consistent with this conclusion. The yield reduction rate was also related to the type, severity, occurrence period and geographical location of the disasters.

In every year from 1961 to 2017, CAD or SAD occurred in Liaoning Province, and the rice yields declined in 23 of the 57 years owing to meteorological disasters (Fig. 9). Although meteorological disasters occurred in the other 34 years, there was no reduction in rice production, which may be related to the gradient of the disaster or the spatial distribution of the rice planting areas. The rice yield reduction rates in 1969 and 1976 were $34.6 \%$ and $15.6 \%$, respectively. In these two years, CAD occurred at 30 stations and SAD occurred at 22 stations, and TD- 1 was the main type of CAD, whereas SAD-d was the main type of SAD. Using statistical data, on the rice planting area of each city in Liaoning Province, the provincial area can be divided into four regions. The first region was Shenyang City, which has the largest rice planting area, accounting for $20 \%-25 \%$ of the total rice planting area; the second region was Panjin City, accounting for 15\%-20\% of the total rice area; the third region encompassed Tieling and other six cities, accounting for nearly $50 \%$ of the total rice area, with each city representing $5 \%-10 \%$; and the fourth region encompassed Jinzhou and five other cities, accounting for $10 \%-15 \%$ of the total, with each city representing 0-5\%. As shown in Fig. 10a,b, TD-1 occurred in the first region in both 1969 and 1976 and in the second region in 1969. SAD-d occurred in the second region in 1976. In the third region, TD-1 occurred at more stations of 1969 than in 1976. The rice area in the first three regions accounted for nearly $80 \%$ of the total rice area, and CAD occurred more often than SAD in these regions. Thus, there was a greater yield reduction rate in 1969 than in 1976.

The occurrence characteristics of single disasters or the risk of yield reduction were analysed in previous studies, but the quantitative effect on rice production was rarely evaluated. Ji et al. ${ }^{26}$ reported that the delayed cold damage in 1961, 1962, 1969, 1972, 1976, 1989 and 1995 was so severe that there was a large reduction in rice production. In our paper, we examined the occurrence of not just one disaster, i.e. delayed cold damage, over time, but also other types of disasters including SAD and CAD. For example, in 1972 and 1976, the disaster scenario affecting the largest number of stations was TD-1, i.e., both delayed cold damage and frost damage occurred in the growing season of rice. In 1961, the most widespread damage came from a single disaster-frost damage. According to the records ${ }^{35}$, Liaoning Province experienced frost damage in 1961, 1962, 1969, 1972, 1976 and 1995, and the rice yield was seriously reduced. Most regions of Liaoning Province experienced both delayed cold damage and frost damage in 1976 and 1995. There was a low temperature during the critical period of rice growth (mid-July to mid-August) in 1995. In 1985, the growing season in most areas was characterized by unusually persistent low temperature and little sunshine. These statistics were basically consistent with the conclusion of this study. In the process of rice production, a variety of disasters occurred caused by low temperature, such as delayed cold damage, frost damage and sterile cold damage.

\section{Conclusions}

There were six possible scenarios of CAD in the rice growing season in Liaoning Province from 1961 to 2017, with OD-1, OD-2, TD-1, TD-2, TD-3 and MD-1 occurring in 32, 0, 35, 3, 20 and 20 years, respectively. Largescale TD-1 only appeared for 6 years, while regional OD-1, TD-1, TD-2 and MD-1 appeared for 1, 3 and 2 years, respectively. The six scenarios were mainly found in the northwest and northeast of Liaoning Province. OD- 1 with a frequency greater than $20 \%$ occurred at three sites and TD- 1 at nine sites. Three sites of OD- 1 and 18 sites of TD-1 showed a disaster occurrence with a frequency in the $10 \%-20 \%$ range. The occurrence frequency of other disasters was less than $10 \%$. The IOC values in the four most common scenarios showed declining trends but the OD-1 scenario showed an upward trend. The distributions and frequency of TD-1 were the highest in the six scenarios.

In the past 57 years, the occurrence of CAD showed a significant downward trend, and the decline rate was more rapid than that of SAD. CAD and SAD occurred in all 57 years. There were 42 years with an IOC value in $\mathrm{CAD}$ lower than that of SAD, and 14 years where it was higher than SAD. Four sites in CAD and one site in SAD had a frequency greater than $50 \%$. There were 13 sites with a frequency between $20 \%$ and $50 \%$ in CAD, and 42 sites in SAD. Compared with SAD, the occurrence range and frequency of CAD was lower, and the interdecadal mean value of the IOC in CAD was lower than that of SAD in all decades except 1971-1980. High frequencies of SAD were mainly found in the northeast of Liaoning Province, while those of CAD were mainly distributed 

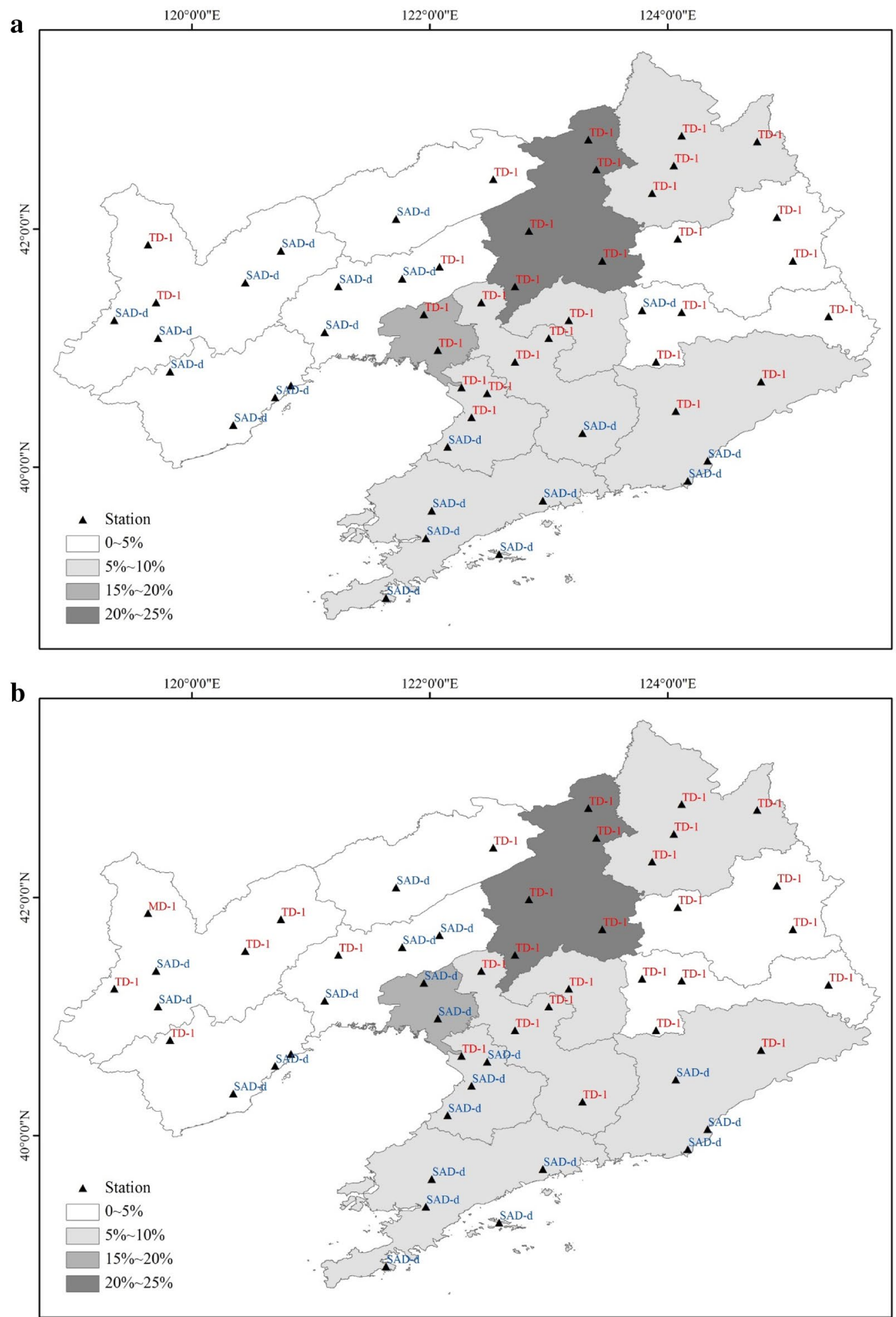

Figure 10. Distributions of the types of agrometeorological disasters and the percentages of rice planting areas in different regions of Liaoning Province in 1969 and 1976 (a: 1969; b: 1976). Maps generated in ArcGIS 9.3.

in the northwest. The major agrometeorological disasters affecting rice production in Liaoning Province were DCD, FD or a combination of the two.

The occurrence frequency and range of SAD and CAD events showed decreased trends in rice cropping areas in the past 57 years. Under the background of climate change, early spring warming, delays in the first frost date and decreases in low temperature events in summer were the main reasons for the decrease of cold disaster events in rice. However, because of the frequent occurrence of climate anomalies, extreme cold events still exist. 
Disasters in SAD-f and OD-1 showed no significant decreasing trend, and even slightly increased. Therefore, both SAD and CAD were still high probability events in the rice growing areas of Liaoning Province. Further study is needed on the causes and characteristics of CAD occurrences in relation to the climate background and dominant weather types because of their complexity.

Compared with SAD, CAD had more scenario types and more complex occurrence processes. Under the CAD scenarios, the effects of different disasters may be magnified, making reductions in rice yields more likely. CAD or SAD occurred in every year from 1961 to 2017, and the rice yields declined in 23 of the 57 years. A comparison of the rice yield reduction rates in the years when CAD or SAD occurred in more than $50 \%$ of stations in Liaoning Province revealed a greater average yield reduction rate in former than in latter. Nearly $80 \%$ of the total rice area in 1969 had a yield reduction rate greater than 10\%, and CAD occurred more often in 1969 than in 1976 in this region, which led to a greater yield reduction rate in 1969 than in 1976. Meteorological disasters occurred in 34 years that showed no reduction in rice production, and this may be related to the gradient of the disaster or the spatial distribution of the rice planting areas. Further controlled field experiments should be conducted to quantify the effects of CAD on rice yield.

Received: 21 December 2020; Accepted: 16 April 2021

Published online: 11 May 2021

\section{References}

1. Yoshida, S. Fundamentals of Rice Crop Science (International Rice Research Institute, 1981).

2. FAO.How to feed the world in 2050. http://www.fao.org (2009).

3. Shimonoa, H., Kannob, H. \& Sawanoc, S. Can the cropping schedule of rice be adapted to changing climate? A case study in cool areas of northern Japan. Field Crop Res. 118, 126-134 (2010).

4. Carriger, S. \& Vallée, D. More crop per drop. Rice Today. 6, 10-13 (2007).

5. Iizumi, T. \& Yokozawa, M. Climate change impact on rice insurance payouts in Japan. J. Appl. Meteorol. Climatol. 47, 2265-2278 (2008).

6. Shimono, H., Hasegawa, T., Moriyama, M., Fujimura, S. \& Nagata, T. Modeling spikelet sterility induced by low temperature in rice. Agron. J. 97, 1524-1536 (2005).

7. Shimono, H., Okada, M., Kanda, E. \& Arakawa, I. Low temperature-induced sterility in rice: Evidence for the effects of temperature before panicle initiation. Field Crop Res. 101, 221-231 (2007).

8. Tani, N. On the prevention measure of the damage from tyhoon in south Kyushu. Bull. Kyushu Agric, Exp. Station 12, 343-387 (1966).

9. Xiong, Q., Deng, Y., Zhong, L., He, H. \& Chen, X. Effects of drought-flood abrupt alternation on yield and physiological characteristics of rice. Int. J. Agric. Biol. 20, 1107-1116 (2018).

10. Teixeira, E. I., Fischer, G., Velthuizen, H. V., Walter, C. \& Ewert, F. Global hot-spots of heat stress on agricultural crops due to climate change. Agric. For. Meteorol. 170, 206-215 (2013).

11. Mamun, E. A., Alfred, S., Cantrill, L. C., Overall, R. L. \& Sutton, B. G. Effects of chilling on male gametophyte development in rice. Cell Biol. Int. 30, 583-591 (2006).

12. Matsui, T., Omasa, K. \& Horie, T. The difference in sterility due to high temperatures during the flowering period among japonicarice varieties. Plant Prod. Sci. 4, 90-93 (2001).

13. Wang, P. et al. A review of cold injury and heat damage to rice growth under global warming. Resour. Sci. 36, 2316-2326 (2014).

14. Zandalinas, S. I., Mittler, R., Balfagón, D., Arbona, V. \& Gómez-Cadenas, A. Plant adaptations to the combination of drought and high temperatures. Physiol. Plant. 162, 2-12 (2018).

15. Suzuki, K., Nagasuga, K. \& Okada, M. The chilling injury induced by high root temperature in the leaves of rice seedlings. Plant Cell Physiol. 49, 433-442 (2008).

16. Perdome, J. A., Conesa, M., Medrano, H., Ribas-Carbó, M. \& Galmés, J. Effects of long-term individual and combined water and temperature stress on the growth of rice, wheat and maize: Relationship with morphological and physiological acclimation. Physiol. Plant. 155, 149-165 (2015).

17. Keles, Y. \& Öncel, I. Response of antioxidative defence system to temperature and water stress combinations in wheat seedlings. Plant Sci. 163, 783-790 (2002).

18. Rollins, J. A. et al. Leaf proteome alterations in the context of physiological and morphological responses to drought and heat stress in barley (Hordeum vulgare L.). J. Exp. Bot. 64, 3201-3212 (2013).

19. Chen. Z., Zhang, J., Wang, C., \& Zheng, J. Application of WOFOST model in simulation of integrated impacts of low temperature and drought on maize yield. Chin. J. Agrometeorol. 28, 440-442+445 (2007).

20. Yang, R. \& Zhou, G. A comprehensive risk assessment of the main maize agro-meteorologial disasters in the three provinces of Northeast China. Acta Meteor. Sin. 73, 1141-1153 (2015).

21. Liu, L., Guo, J. \& Gao, S. Evaluation on the effect of low temperature and drought on maize. Meteorol. Month. 32, 116-120 (2006).

22. Wu, R. et al. Combination effects of elevated O3 and enhanced UV-B radiation on biomass and yield of soybean. Chin. J. Agrometeorol. 33, 207-214 (2012).

23. Wang, C. et al. Effects of Post-Anthesis waterlogging, high temperature and their combination on starch compositions and pasting properties in wheat grains. Sci. Agric. Sin. 48, 813-820 (2015).

24. Wang, Y., Xu, S., Ma, J. \& Cui, B. Effects of heat and drought stress on the photosynthetic characteristicsand chlorophyll fluorescence parameters of Bletillastriata. J. Henan Agric. Univ. 52, 199-205 (2018).

25. Mittler, R. \& Blumwald, E. Genetic engineering for modern agriculture: Challenges and perspectives. Annu. Rev. Plant Biol. 61, 443-462 (2010).

26. Ji, R., Yu, W., Wu, J., Feng, R. \& Zhang, Y. Effect of climatic mean value change on the evaluation result of rice delayed cold damage in Liaoning Province, Northeast China. Chin. J. Appl. Ecol. 26, 1695-1703 (2015).

27. Ji, R., Yu, W., Feng, R., Wu, J. \& Zhang, Y. Construction and application of ricesterile-type cold damage index in cold area: A case study of Liaoning Province. Prog. Geogr. 36, 437-445 (2017).

28. Yu, W. et al. Identification and characteristics of multiple agrometeorological disaster of maize in Liaoning Province China. Chin. J. Appl. Ecol. 32, 241-251 (2021).

29. Jiang, L. et al. Sterile type cool injury of rice during booting stage and its impacts on rice yield in Heilongjiang province. Chin. J. Agrometeorol. 30, 463-468 (2009).

30. Ma, S., Wang, Q., Wang, C. \& Huo, Z. Climate risk and economy vulnerability of rice chilling damage and division in Northeast China. Geogr. Res. 30, 931-939 (2011).

31. Han, Y., Fang, S., Liang, H., Zhou, L. \& Zhou, G. Disaster risk regionalization of rice based on its reduction probability in Liaoning Province. Acta Ecol. Sin. 37, 8077-8088 (2017). 
32. Xi, Z., Ma, S. \& Ji, L. Spatial-temporal characteristics of prolong-type rice chilling damage and its relationship with climate change in Northeast China. Geogr. Res. 33, 1373-1382 (2014).

33. Hu, C. et al. Characteristics of severe cold disasters and its responses to regional climate warming in Northeast China. Meteorol. Sci. Technol. 43, 744-749 (2015).

34. Tan, F., Wang, J. \& Cheng, L. Temperature suitability of rice and its variation in Northeast China. Chin. J. Ecol. 36, 719-724 (2017).

35. Editorial Committee of China Meteorological Disaster Record.China Meteorological Disaster Record (Liaoning Volume) Beijing: China Meteorological Press pp322 (2005).

\section{Acknowledgements}

This study was supported by the Provincial Key R\&D Project of Department of Science and Technology of Liaoning Province, China (No. 2019JH2/10200018, No. 2017210001), the National Key R\&D Program of China (No. 2018YFD0300309-02); and the Project of the Institute of Atmospheric Environment, China Meteorological Administration, Shenyang (No. 2018SYIAEHZ1).

\section{Author contributions}

R.J. contributed to the conception and design, data analysis and interpretation, draft and revision of the manuscript. W.Y. contributed to the data analysis of the manuscript. R.F., J.W. collected the data. Y.Z. contributed to the revision of the manuscript.

\section{Competing interests}

The authors declare no competing interests.

\section{Additional information}

Correspondence and requests for materials should be addressed to R.J.

Reprints and permissions information is available at www.nature.com/reprints.

Publisher's note Springer Nature remains neutral with regard to jurisdictional claims in published maps and institutional affiliations.

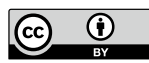

Open Access This article is licensed under a Creative Commons Attribution 4.0 International License, which permits use, sharing, adaptation, distribution and reproduction in any medium or format, as long as you give appropriate credit to the original author(s) and the source, provide a link to the Creative Commons licence, and indicate if changes were made. The images or other third party material in this article are included in the article's Creative Commons licence, unless indicated otherwise in a credit line to the material. If material is not included in the article's Creative Commons licence and your intended use is not permitted by statutory regulation or exceeds the permitted use, you will need to obtain permission directly from the copyright holder. To view a copy of this licence, visit http://creativecommons.org/licenses/by/4.0/.

(C) The Author(s) 2021 